\title{
Asthma, outdoor air quality and the Olympic Games
}

\author{
Donald C. McKenzie MD PhD, Louis-Philippe Boulet MD
}

Published at www.cmaj.ca on Aug. 7, 2008. Revised Aug. 28, 2008.

$\infty \infty$

See related News article for update on air quality, page 523

$\mathrm{W}$ ith the world's best athletes gathered in Beijing for the 2008 Olympic Games, the sport community is waiting to see what the impact of the environment and air quality might be on athletes' performance. Speculation by the media has painted an apprehensive picture, but what are the real concerns regarding the performance of these extraordinary athletes, especially those who have asthma?

In this article, we describe the available evidence of the effect of air quality on performance, especially as it pertains to athletes with asthma. We searched MEDLINE using the key words "athletes," "sports," "asthma," "respiratory," "allergy," "airway hyperresponsiveness," "air quality," "pollution" and "exercise." We also participated in a review of past and recent research in this domain by international experts during an International Olympic Committee meeting in Lausanne, Switzerland, in January 2008.

\section{Respiratory adaptations in Olympic athletes}

The Olympic athlete is unique. Traditional views of the determinants of physical performance in healthy individuals document the importance of oxygen transport to the working skeletal muscles. It is also viewed that the capacity of the pulmonary system (respiratory muscles, airways and lung parenchyma) is more than adequate to meet the demands for ventilation and gas exchange. However, in Olympic athletes, years of training have increased the capacity of cardiac and skeletal muscles to deliver and use oxygen such that the demands placed on the airways, chest wall and alveoli to maintain gas exchange cannot be met. During heavy exercise at sea level, in many healthy, highly trained endurance athletes, arterial oxygen concentration can fall precipitously from normal levels to values seen in patients with chronic obstructive lung disease. This is reflected in the development of exerciseinduced arterial hypoxemia, which occurs transiently in about $50 \%$ of athletes during peak exercise.

Changes in exercise-induced arterial hypoxemia have a measurable effect on maximal aerobic capacity in highly trained athletes. On average, the effect is about a $1 \%$ decrement in maximal aerobic capacity for each $1 \%$ decrement in percent arterial oxygen saturation. ${ }^{2}$ It has also been shown that these athletes experience the greatest decrement in aerobic capacity when they perform in hypoxic environments. Even relatively small changes in altitude (about $1000 \mathrm{~m}$ ), which does not effect arterial oxygen saturation or maximal

\section{Key points}

- Many athletes with asthma compete successfully at international events, including the Olympics Games.

- The heat and humidity in the Beijing region present a formidable challenge to all athletes.

- Poor air quality can affect the performance of athletes, especially those who have asthma. Pollutants can trigger and exacerbate symptoms, affect airways and increase the risk of exercise-induced-bronchospasm.

- The risk of respiratory problems is greatest for athletes participating in outdoor endurance events at sites with poor air quality.

- Athletes in the Paralympic Games who have spinal cord lesions affecting coughing and breathing mechanics will also be at increased risk.

aerobic capacity appreciably in untrained individuals, produces substantial hypoxemia at the high work rates achieved by elite athletes. This results in significant decrements in both aerobic power and endurance performance. ${ }^{3,4}$

\section{Respiratory problems in Olympic athletes}

As a result of years of training in preparation for events such as the Olympic Games, elite athletes often experience intraand extrathoracic respiratory problems and may also experience expiratory flow limitation. In our opinion, the most difficult respiratory problem to treat in this population is the sudden paradoxical narrowing of the glottis, usually a manifestation of vocal cord dysfunction. Inspiratory stridor is an important differentiating symptom. The reported prevalence among athletes competing outdoors is $8.3 \% .^{5}$ Vocal cord dysfunction usually occurs during very heavy exercise, when the inspiratory flow rates are extreme. This condition immediately results in dyspnea, hypoxemia, retention of carbon dioxide and compromised performance. It is not uncommon for these athletes to withdraw from competition when this problem occurs. Treatment is difficult because it often involves a variety of therapies and modification of activity. Approaches that may be considered include the management of any associated conditions (e.g., gastroesophageal reflux disease) as well as speech and relaxation therapy. ${ }^{6}$ Other treatments that have been used

From the Division of Sports Medicine and School of Human Kinetics, University of British Columbia (McKenzie), Vancouver, BC; and the Institut de cardiologie et de pneumologie de l'Hôpital Laval (Boulet), Québec, Que. 
include Botox injections, inhalation of heliox (21\% oxygen in helium) and training of the respiratory muscles and breathing mechanics with a resistive device.

In general, the airways are capable of meeting the respiratory demands of heavy work within the limits of the normal maximal flow volume loop. However, in some athletes, the increase in minute ventilation may cause a portion of the tidal breathing loop to intersect with the maximal flow volume loop. This expiratory flow limitation and may be present because of the substantial demand on the pulmonary system with intense exercise. Trained female athletes may be particularly susceptible to expiratory flow limitation because their airways are smaller in diameter, they have lower peak flow rates and their lung volumes are smaller than those of their male counterparts. ${ }^{7}$ Expiratory flow limitation may influence performance by contributing to exercise-induced arterial hypoxemia

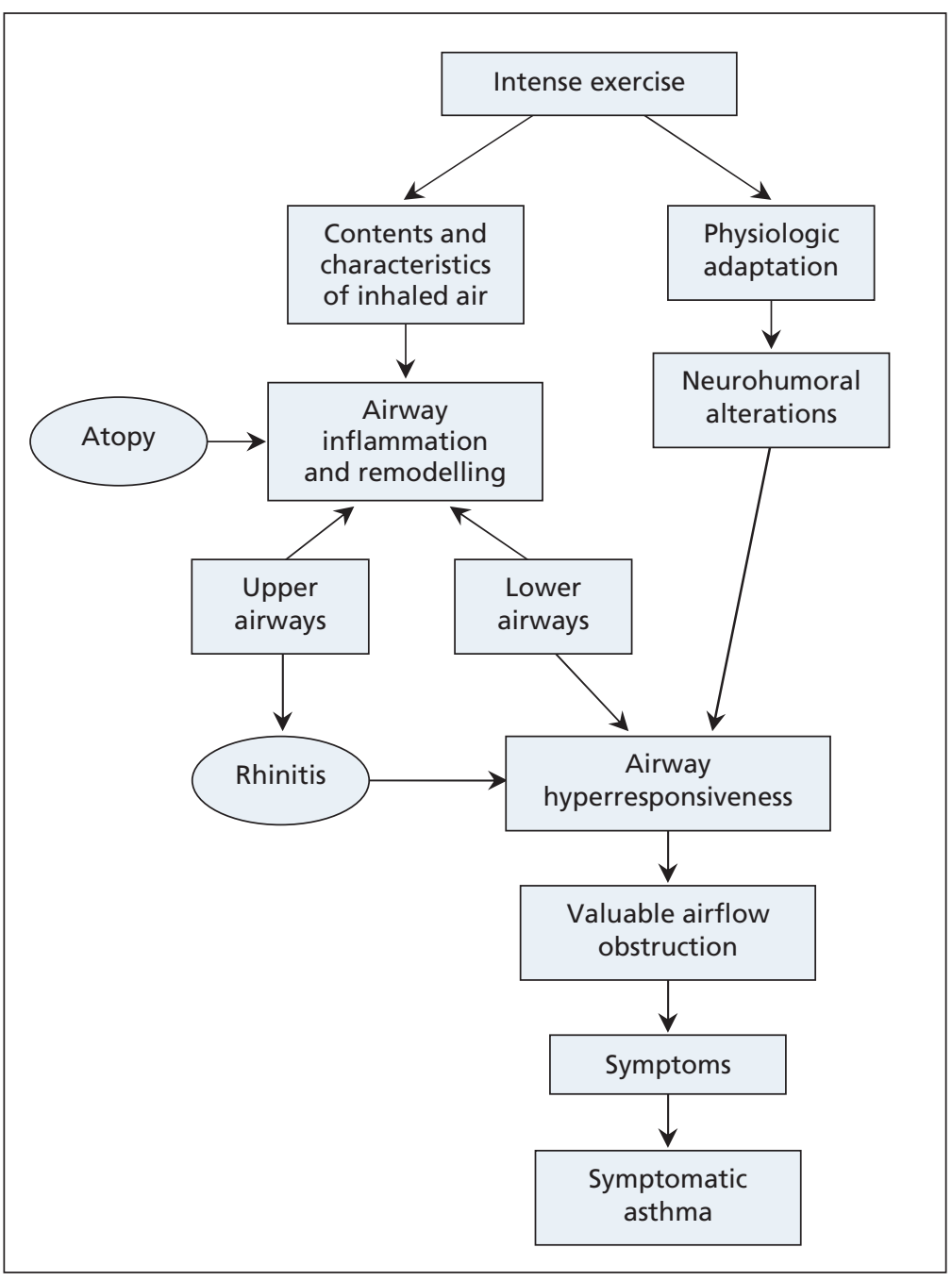

Figure 1: Proposed mechanism leading to the development of asthma in athletes. Intense, repetitive exercise, characteristic of highly trained athletes, leads to high minute ventilation, which increases the exposure of the airways to mechanical stress and environmental contaminants. This induces airway inflammation and structural changes (remodelling), which are responsible for the development of airway hyperresponsiveness, airway obstruction and asthma. and by increasing the work of breathing at the expense of meeting the metabolic needs of working skeletal muscles.

Much more common are conditions affecting the lower airway, such as asthma. Asthma is highly prevalent in the general population, and even more prevalent among athletes. ${ }^{89}$ Airway hyperresponsiveness has been reported to occur in $25 \%-79 \%$ of athletes in endurance sports, and in about $20 \%$ of athletes in power and speed sports. ${ }^{10,11}$ The prevalence of asthma and airway hyperresponsiveness, therefore, seems to be influenced by the type of sport or the environmental conditions during training, or both.

Asthma is a chronic inflammatory disorder of the airways associated with airway hyperresponsiveness and variable airway obstruction and is considered responsible for recurrent episodes of breathlessness, wheezing, chest tightness, phlegm production and coughing. ${ }^{12}$ Asthma can be triggered by various stimuli, including allergens in sensitized individuals, respiratory irritants (e.g., air pollutants), cold air and exercise. Exercise-induced asthma is considered to be due to the cooling, but mostly the drying, of the airways following exercise-induced hyperventilation. The result is the development of a hyperosmolar airway fluid. Rewarming of the airways due to a post-exercise increase in airway blood flow and transient plasma transudation may also contribute to the induced bronchoconstriction. ${ }^{13,14}$

\section{Exercise and asthma}

Physical activity is often recommended to patients with asthma, and regular exercise can improve asthma control. However, there is mounting evidence that frequent, intense exercise by highly trained athletes contributes to the development of asthma. Indeed, long-term endurance training may influence airway structure and function and lead to airway hyperresponsiveness. ${ }^{10}$ Various factors could contribute to the development of asthma in athletes, including environmental exposures, mechanical stress to the airways, increased prevalence of respiratory infections and dysautonomia. ${ }^{10,15}$ The mechanisms by which these factors could influence asthma development may be related to their ability to induce airway inflammation and structural changes (remodelling). These processes are considered to be responsible for the development of airway hyperresponsiveness and variable or persistent airway obstruction. ${ }^{11-17}$

Airway inflammation and remodelling have been observed in athletes, even those without asthma. $^{18,19}$ In general, bronchial inflammation is of a mixed type, with increased neutrophil and eosinophil counts. In swimmers, airway inflammation and potentiation of the effects of allergens on airways from chlorine derivatives result in epithelial damage, which has been proposed as a mechanism that leads to airway hyperresponsiveness, respiratory symptoms and asthma. ${ }^{20}$ Furthermore, mechanical 
stress caused by intense breathing efforts may also damage the airway epithelium and promote airway remodelling ${ }^{21}$ (Figure 1).

It is therefore possible that, in highly trained athletes, environmental contaminants and environmental conditions during training (e.g., chlorine derivatives in swimming pools, cold air, presence of relevant allergens or high levels of pollutants) may contribute to the development of variable airway obstruction, airway hyperresponsiveness and symptomatic asthma. It is reassuring, however, that a few studies have suggested that these long-term changes in lung function in athletes may be at least partially reversible after cessation of training. ${ }^{22,23}$

\section{The environment and asthma}

The environment during summer Olympic Games often provides an additional challenge to athletes in the form of heat, humidity and poor air quality. Such was the case at the Olympic Games in 1984 in Los Angeles, in 1992 in Barcelona, in 1996 in Atlanta and in 2004 in Athens. The 2008 Olympic Games have attracted a great deal of attention because of the record of poor air quality in the Beijing region. ${ }^{24}$

The Beijing Environment Protection Bureau collected environmental data (temperature, wind, humidity and air-quality readings) from Aug. 8 to 29, 2007, the same time of year when the Olympic Games would be held the following year. Subsequently, the International Olympic Committee's Medical Commission evaluated the data on the basis of the World Health Organization's 2005 interim target standards. The findings indicated that the health of athletes was largely not impaired. This finding was upheld by the fact that no health issues related to air quality were reported to the International Olympic Committee by any of the team physicians who looked after athletes competing during the August 2007 test events. Nor were any such problems reported at the World Junior Athletics Championships that were held in August $2006 .^{25}$

Although air quality is often flagged as a concern before Olympic Games, it is rarely acknowledged as a factor that influenced performance once the Games are over. Increased heat and humidity are a constant concern at the summer Olympic Games. As a consequence, medical personnel, coaches and athletes have developed preventive and treatment strategies.

The relation between air quality and respiratory health problems is substantial. ${ }^{26,27}$ The primary air pollutants are ozone, sulfur dioxide, nitrogen dioxide and particulate matter. Carbon monoxide is also of interest to the athlete because of its ability to compete for oxygen on hemoglobin. Powergenerating plants, road transport and industry are the primary sources of these compounds. Ozone is not emitted directly from any industrial source in significant quantities. At ground level, it is primarily generated by a series of chemical reactions driven by sunlight. Particulate matter is associated with a range of effects on health, including the respiratory and cardiovascular systems. People with existing lung and heart disease are at risk of death from exposure to high levels of particulate matter.

\section{Consequences of asthma in athletes}

Many athletes with asthma compete successfully at international events, including the Olympics Games. However, exercise-induced bronchoconstriction may reduce their performance. Uncontrolled asthma may be associated with a reduced effort tolerance and more marked exercise-induced bronchoconstriction. In athletes with asthma, the diameters of the large and small airways are likely compromised during exercise, and even small changes will have negative effects on the work of breathing and gas exchange. Consequently, exerciseinduced arterial hypoxemia is prevalent among athletes with asthma during high-intensity exercise..$^{28,29}$

With exposure to an environment that has poor air quality, air pollutants may trigger asthma symptoms, usually in a dosedependent manner. ${ }^{30,31}$ McCreanor and colleagues, ${ }^{32}$ in a welldesigned, randomized crossover study, showed that exhaust emissions from motor vehicles with diesel engines exacerbated asthma and increased the severity of asthma symptoms and medication use. Air pollutants may also enhance allergen-induced airway responses, as has been shown in animal models. ${ }^{33}$ With the high minute ventilation seen during exercise, the effects of exposure to these pollutants are more noticeable in athletes than in nonathletes and likely more evident in people with asthma than in those without asthma. Even healthy people may experience the detrimental influences of pollutants. Rundell and colleagues $^{31}$ found that, in athletes without asthma, acute exposure to particulate matter, typical of urban environments, resulted in reduced exercise performance. Inhalation of particulate matter possibly induces bronchoconstriction through the production of reactive oxygen species and their influence on leukotriene pathways. In this regard Rundell and colleagues ${ }^{34}$ reported that bronchoconstriction provoked by inhalation of fine and ultrafine particulate matter was attenuated by a single dose of montelukast.

Because poor air quality may exacerbate asthma, increase symptoms and result in poor performance, optimal control of this condition is essential to allow highly trained athletes to compete. In the last decade, much has been written about the optimal management of asthma. Current consensus guidelines, such as the Global Initiative on Asthma ${ }^{35}$ and Canadian guidelines, ${ }^{36}$ have integrated these findings into their recommendations. Recent task forces have summarized the current knowledge regarding highly trained athletes. ${ }^{37,38}$

\section{Management of asthma in Olympic athletes}

Current recommendations indicate that asthma in highly trained athletes should be managed according to existing general national and international asthma management guidelines. ${ }^{35,36}$ Special consideration, however, should be given to the diagnosis of asthma in athletes and assessment of asthma control; preventive measures; the management of exercise-induced asthma; and medication use, which should comply with the criteria of regulatory agencies. The overall management of asthma in the athlete is summarized in Box 1.

In the Olympic athlete, the prevention of exercise-induced bronchoconstriction will help maximize sport performance. In the presence of symptoms compatible with asthma, the diag- 
Box 1: Individualized management plan for athletes with asthma*

- Confirm diagnosis with appropriate testst

- Identify triggers (particularly allergens and air pollutants)

- Check for comorbid conditions (e.g., rhinitis, gastroesophageal reflux disease, vocal cord dysfunction)

- Determine severity of asthma and level of asthma control according to current guidelines

- Explain goals of treatment

- Initiate an education program; refer athlete to an asthma educator if possible

- Determine environmental control measures to be undertaken

- Prescribe medication needed to achieve and maintain asthma control in keeping with current regulations for medication use by athletes*

- Explain how to minimize exercise-induced bronchoconstriction

- Design an action plan for the management of exacerbations

- Regularly assess asthma control, effort tolerance, inhaler technique, comorbidities, environmental exposures, and treatment and educational needs

*It is important to comply with the anti-doping regulations of the International Olympic Committee ${ }^{39}$ and the World Anti-Doping Agency. ${ }^{40}$ tEucapneic voluntary hyperpnea, exercise, methacholine, hypertonic saline, mannitol challenge tests.

nosis needs to be confirmed by objective means, according to criteria requested by sports authorities for athletes competing at high level. This information can be found on the website of the International Olympic Committee. ${ }^{39}$ Triggering factors, particularly exposure to sensitizing agents, should be identified. Allergy skin tests should be conducted if results of such tests are not already available. Comorbid conditions frequently observed in athletes, such as rhinitis, vocal cord dysfunction or gastroesophageal reflux, may affect asthma control or act as confounders, and investigation and treatment is necessary. ${ }^{41,42}$

Education is an essential component of asthma management, especially among athletes. ${ }^{43}$ Environmental control and avoidance of triggers are also important for Olympic athletes. The potential detrimental effects of chlorine derivatives in swimming pools should be minimized by proper management of the pool environment. ${ }^{44}$ Emotions and stress may worsen asthma symptoms, but good asthma control may help reduce their effects.

Pharmacotherapy for asthma in athletes should be individualized. It should be based on reduction of inflammation, mainly with the use of inhaled corticosteroid therapy (the best drug therapy for asthma control), and optimization of airway control with other add-on therapies as needed. Rapid-acting $\beta_{2}$-agonists are the most frequently used medications to relieve acute intermittent symptoms and to prevent exercise-induced bronchoconstriction. Protection against exercise-induced bronchoconstriction diminishes, however, when these agents are used regularly. The minimum dose and frequency required to minimize this loss of effect are recommended. ${ }^{45}$ Such tachyphylaxis to their bronchoprotective effects occurs after only a few days of use and is not antagonized by inhaled corticosteroid therapy, which can reduce exercise-induced bronchoconstriction in most people with asthma after a few weeks of regular use. ${ }^{46}$

If asthma is not controlled by a low dose of inhaled corticosteroid therapy, current guidelines suggest that a long-acting $\beta_{2}-$ agonist should be prescribed to improve such control. Therapy with a leukotriene receptor antagonist, such as montelukast, is a second option for this purpose. ${ }^{35,36}$ Monotherapy with a longacting $\beta_{2}$-agonist may be associated with a worsening of asthma and trigger severe asthma events and should be avoided. For the prevention of exercise-induced bronchoconstriction, inhaled $\beta_{2}$ agonist therapy is best for preventing exercise-induced bronchoconstriction and, when used 10-15 minutes before exercise, may reduce airway response to exercise..$^{47} \mathrm{~A}$ low-intensity exercise (warm up) before exertion may induce a "refractory period" to exercise and reduce the likelihood of exercise-induced bronchoconstriction for a period of about 2 hours. ${ }^{48}$

\section{Use of medications before and during the Olympic Games}

Olympic athletes must comply with regulations of the International Olympic Committee ${ }^{39}$ and the World Anti-Doping Agency $^{40}$ for the use of all medications. There are severe sanctions for violation of these rules. For most asthma medications, a Therapeutic Use Exemption application form must be completed by the athlete and a physician. Athletes wishing to use an inhaled $\beta_{2}$-agonist at the Olympic Games must document the need for this medication via pulmonary function testing and submit an application to the International Olympic Committee's Medical Commission, which is responsible for doping control during the Olympic Games. Only formoterol, salbutamol, salmeterol and terbutaline, when administered by inhalation, are approved $\beta_{2}$-agonists.

\section{Beijing's preparation for the Olympic Games}

In response to concerns about air quality in the Beijing region and with a desire to present a positive picture to the rest of the world, the government of China has implemented several strategies to improve air quality during the Olympic and Paralympic Games. Private traffic has been reduced by $50 \%$, and $70 \%$ of government vehicles have been taken off the roads. There are driving restrictions for trucks, improvement in fuel quality, and all construction will be stopped. Chemical, steel and building plants will be closed, and power generation reduced by $30 \%$. However, a significant percentage of the pollution (about 35\%) at the Olympic Stadium can be attributed to sources outside of Beijing. ${ }^{24}$ Controlling only local sources of pollution may not be sufficient to achieve the air quality goal set for the Beijing games.

\section{Athletes' preparation for the Beijing Olympic Games}

Heat and humidity represent a clear threat to performance at the Beijing Olympic Games. These conditions are predictable, and 
prevention and treatment protocols are in place for all athletes. Air quality is not predictable, and there is significant day-today variability in the measured levels of pollutants at the different Olympic venues. Accordingly, it is prudent to prepare for situations that have the potential to influence performance.

Some teams are staging (last preparation phase) in areas that have good air quality, permit acclimatization to the heat and humidity and are in a time zone close to Beijing's. Singapore, Japan and Australia have been mentioned in this regard. This strategy allows the athletes to arrive in Beijing just before competition and would minimize their exposure to air pollution. Other teams are staging in Beijing to familiarize themselves with the area, participate in opening ceremonies and adjust to the media attention and the excitement that accompany the Olympic Games. Although acclimatization to most of the air pollutants is not possible, a tachyphylaxis to the effects of ozone does occur over 1 or 2 days of exposure. It is quite possible that medical officers from different countries will request approval from the International Olympic Committee's Medical Committee for athletes without asthma to use inhaled corticosteroids if respiratory symptoms develop. The empirical use of montelukast as prophylaxis for poor air quality is an option that will be considered by many clinicians at the Olympic Games.

Whenever possible, athletes should train early in the day or the evening, when air quality is best. They should avoid training in the extreme conditions of temperature and humidity. Mechanical barriers such as facemasks may counteract the effects of some pollutants or cold air, but they are usually not tolerated during exercise given the high minute ventilation required during training and competition.

Several national Olympic committees and individual teams have recommended screening athletes for airway hyperresponsiveness and asthma. Anecdotally, this has resulted in some notable surprises, particularly among swimmers. Because poor air quality will affect athletes with asthma, it is reasonable to identify individuals that may have this condition (tested on the basis of family history, allergies and symptoms) and optimize airway control in athletes with evidence of asthma before they arrive in Beijing.

Most air pollutants act as irritants, and treatment of their effects is primarily symptomatic. Suggestions for providing relief from these symptoms are listed in Table 1.

\section{Knowledge gaps}

The Olympic athlete is rare, and the majority of testing is done to monitor training. It is difficult to attract this population to participate in randomized controlled studies that do not have performance as the primary outcome measure.

Although there are an increasing number of publications on the topic of asthma and exercise, recommendations for the management of asthma in highly trained athletes come from consensus statements for the most part and a limited number of randomized clinical trials involving small numbers of participants.

For ethical reasons, there is little experimental research that has involved exposing highly trained athletes to an environment with poor air quality.

There is no research into the effects of exercise and poor air quality on athletes, with or without asthma, who participate in in the Paralympic Games. Many of these individuals have compromised respiratory health because of spinal cord lesions that lead to altered breathing mechanics and a poor cough reflex. The potential for difficulties in Paralympic athletes would appear to be substantial, yet this has not received any attention in the literature.

More studies are needed on the mechanisms of development and remission of asthma in athletes and on how to protect the airways against these changes.

More research is also needed into the optimal management of asthma in athletes and the long-term consequences of participating in sport on their respiratory health.

Table 1: Management of symptoms in athletes competing in venues with poor air quality

\begin{tabular}{lll}
\hline Location & \multicolumn{1}{c}{ Symptoms } & \multicolumn{1}{c}{ Suggested treatment* } \\
\hline Oral cavity & Cough, sore throat & $\begin{array}{l}\text { Hydration, treatment of symptoms with } \\
\text { mouth rinses, gargles and lozenges }\end{array}$ \\
$\begin{array}{l}\text { Nose and } \\
\text { sinus }\end{array}$ & $\begin{array}{l}\text { Rhinitis (allergic or not), sinus } \\
\text { discomfort/congestionheadache }\end{array}$ & $\begin{array}{l}\text { Nasal spray (saline, cromolyn sodium, } \\
\text { ipratropium bromide or inhaled nasal } \\
\text { corticosteroid), antihistamine, } \\
\text { decongestant }\end{array}$ \\
Eyes & $\begin{array}{l}\text { Eye discomfort/burning, conjunctivitis, } \\
\text { watery discharge }\end{array}$ & $\begin{array}{l}\text { Lubricating eye drops, artificial tears, } \\
\text { antihistamine if allergic conjunctivitis }\end{array}$ \\
Skin & $\begin{array}{l}\text { Rash in athletes with allergic } \\
\text { sensitivities }\end{array}$ & $\begin{array}{l}\text { Treatment of symptoms with topical } \\
\text { creams (with or without corticosteroids), } \\
\text { sunscreen } \\
\text { Inhaled corticosteroid, }+\beta_{2} \text {-agonist, } \neq \\
\text { montelukast, inhaled sodium cromolyn }\end{array}$ \\
\hline
\end{tabular}

* Treatments to be considered according to the underlying condition. The 2008 list of prohibited medications issued by the World Anti-Doping Agency (www.wada-ama.org/rtecontent/document/2008_List_En.pdf) should be reviewed before any medication is given, regardless of the route of administration.

tMedication to be prescribed according to current guidelines.

¥The use of $\beta_{2}$-agonists at the Olympic Games requires testing to document need. 


\section{Summary}

The environment can have a significant effect on performance of Olympic athletes. The heat and humidity in the Beijing region, as in previous summer Olympic events, present a formidable challenge to athletes. Poor air quality, if present, will have a psychological and possibly physiologic effect on the performance of all athletes. Athletes who have asthma may be further compromised by poor air quality. Ozone, oxides of sulfur and nitrogen as well as particulate matter increase airway inflammation, which in turn will trigger or exacerbate symptoms and possibly decrease performance. The risk is greatest among athletes with asthma who will be competing outdoors in endurance events at Olympic venues where the air quality is poor. In addition, Paralympic athletes with spinal cord lesions are at increased risk because of their compromised ability to cough and altered breathing mechanics.

Competing interests: Louis-Philippe Boulet has served on advisory boards for AstraZeneca, GlaxoSmithKline, Novartis and Schering-Plough; he has received honoraria from Altana, AstraZeneca, GlaxoSmithKline, Merck Frosst, Novartis and MedImmune; and has received research support from Alexion, Asthmatx, AstraZeneca, Boehringer-Ingelheim, Ception, GlaxoSmithKline, Genentech, IVAX, MedImmune, Merck Frosst, Novartis, Schering-Plough, Topigen and Wyeth. No competing interests declared by Donald McKenzie.

Contributors: Both authors contributed substantially to the development of the article, critically revised it for important intellectual content and approved the final version for publication.

\section{REFERENCES}

1. Dempsey JA, Wagner PD. Exercise-induced arterial hypoxemia. J Appl Physiol 1999;87:1997-2006.

2. Powers SK, Lawler J, Dempsey JA, et al. Effects of incomplete pulmonary gas exchange on $\mathrm{VO}_{2}$ max. J Appl Physiol 1989;66:2491-5.

3. Gore CJ, Little SC, Hahn AG, et al. Reduced performance of male and female athletes at $580 \mathrm{~m}$ altitude. Eur J Appl Physiol 1997;75:136-43.

4. Koskolou MD, McKenzie DC. Arterial hypoxemia and performance during intense exercise. Eur J Appl Physiol Occup Physiol 1994;68:80-6.

5. Rundell KW, Spiering BA. Inspiratory stridor in elite athletes. Chest 2003;123: 468-74.

6. Fallon KE. Upper airway obstruction masquerading as exercise induced bronchospasm in an elite road cyclist. Br J Sports Med 2004;38:E9.

7. Guenette JA, Witt JD, McKenzie DC, et al. Respiratory mechanics during exercise in endurance-trained men and women. J Physiol 2007;581:1309-22.

8. Turcotte H, Langdeau JB, Thibault G. at al. Prevalence of respiratory symptoms in an athlete population. Respir Med 2003;97:955-63.

9. Helenius IJ, Tikkanen HO, Haahtela T. Association between type of training and risk of asthma in elite athletes. Thorax 1997;52:157-60.

10. Langdeau JB, Boulet LP. Prevalence and mechanisms of development of asthma and airway hyperresponsiveness in athletes. Sports Med 2001;31:601-16.

11. Langdeau JB, Turcotte H, Bowie DM, et al. Airway hyperresponsiveness in elite athletes. Am J Respir Crit Care Med 2000;161:1479-84.

12. Lemanske RF Jr, Busse WW. Asthma. J Allergy Clin Immunol 2003;111:S502-19.

13. Anderson SD, Daviskas E. The mechanism of exercise-induced asthma is ... . J Allergy Clin Immunol 2000;106:453-9.

14. Parsons JP, Mastronarde JG. Exercise-induced bronchoconstriction in athletes. Chest 2005;128:3966-74.

15. Haahtela T, Malmberg P, Moreira A. Mechanisms of asthma in Olympic athletes — practical implications. Allergy 2008;63:685-94.

16. Bergeron C, Boulet LP. Structural changes in airway diseases: characteristics, mechanisms, consequences, and pharmacologic modulation. Chest 2006;129:1068-87.

17. Helenius I, Lumme A, Haahtela T. Asthma, airway inflammation and treatment in elite athletes. Sports Med 2005;35:565-74.

18. Sue-Chu M, Henriksen AH, Bjermer L. Non-invasive evaluation of lower airway inflammation in hyper-responsive elite cross-country skiers and asthmatics. Respir Med 1999;93:719-25.

19. Karjalainen E-M, Laitinen A, Sue-Chu M, et al. Evidence of airway inflammation and remodeling in ski athletes with and without bronchial hyperresponsiveness to methacholine. Am J Respir Crit Care Med 2000;161:2086-91.

20. Bernard A. Chlorination products: emerging links with allergic diseases. Curr Med Chem 2007;14:1771-82.
21. Tschumperlin DJ, Drazen JM. Chronic effects of mechanical force on airways Annu Rev Physiol 2006;68:563-83.

22. Kujala UM, Sarna S, Kaprio J, et al. Asthma and other pulmonary diseases in former elite athletes. Thorax 1996;51:288-92.

23. Helenius I, Rytilä P, Sarna S, et al. Effect of continuing or finishing high-level sports on airway inflammation, bronchial hyperresponsiveness, and asthma: A 5year prospective follow-up study of 42 highly trained swimmers. J Allergy Clin Immunol 2002;109:962-8.

24. Streets DG, Fu JS, Jang CJ, et al. Air quality during the 2008 Beijing Olympic Games. Atmos Environ 2007;41:480-92. Available: www.anl.gov/Media_Center /News/2007/Beijing_report_final.pdf (accessed 2008 Aug 5).

25. IOC Medical Commission. NOCS discuss air quality in Beijing. International Olympic Committee; 2008. Available: www.olympic.org/uk/organisation /commissions/medical/full_story_uk.asp?id=2533 (accessed 2008 Aug 5).

26. Gauderman WJ, Avol E, Gilliland F, et al. The effect of air pollution on lung development from 10 to 18 years of age. $N$ Engl J Med 2004;351:1057-67.

27. McConnell R, Berhane K, Gilliland F, et al. Air pollution and bronchitic symptoms in southern California children with asthma. Environ Health Perspect 1999;107: 757-60.

28. Haverkamp HC, Dempsey JA, Miller JD, et al. Gas exchange during exercise in habitually active asthmatic subjects. J Appl Physiol 2005;99:1938-50.

29. Haverkamp HC, Dempsey J, Pegelow DF, et al. Treatment of airway inflammation improves exercise pulmonary gas exchange and performance in asthmatic subjects. J Allergy Clin Immunol 2007;120:39-47. Epub 2007 Apr 23.

30. Bernstein JA, Alexis N, Barnes C, et al. Health effects of air pollution. J Allergy Clin Immunol 2004;114:1116-23.

31. Rundell KW, Caviston R. Ultrafine and fine particulate matter inhalation decreases exercise performance in healthy subjects. J Strength Cond Res 2008;22:2-5.

32. McCreanor J, Cullinan P, Nieuwenhuijsen MJ, et al. Respiratory effects of exposure to diesel traffic in persons with asthma. N Engl J Med 2007;357:2348-58.

33. Kleinman MT, Sioutas C, Froines JR, et al. Inhalation of concentrated ambient particulate matter near a heavily trafficked road stimulates antigen-induced airway responses in mice. Inhal Toxicol 2007;19(Suppl 1):117-26.

34. Rundell KW, Spiering BA, Baumann JM, et al. Bronchoconstriction provoked by exercise in a high-particulate-matter environment is attenuated by montelukast. Inhal Toxicol 2005;17:99-105.

35. Global Initiative for Asthma (GINA). GINA report: global strategy for asthma management and prevention. Hamilton (ON): GINA; 2007: Available: www .ginasthma.org/GuidelineItem.asp?intId=60 (acccessed 2008 Aug 5).

36. Lemière C, Bai T, Balter M, et al. Adult asthma consensus guidelines update 2003. Can Respir J 2004;11(Suppl A):9A-18A

37. Carlsen KH, Anderson SD, Bjermer L, et al; European Respiratory Society; European Academy of Allergy and Clinical Immunology; GA(2)LEN. Treatment of exercise-induced asthma, respiratory and allergic disorders in sports and the relationship to doping: Part II of the report from the Joint Task Force of European Respiratory Society (ERS) and European Academy of Allergy and Clinical Immunology (EAACI) in cooperation with GA(2)LEN. Allergy 2008;63:492-505.

38. Fitch DK, Sue-Chu M, Anderson SD, et al. Asthma and the elite athlete: summary of the International Olympic Committee's consensus conference, Lausanne, Switzerland, January 22-24, 2008. J Allergy Clin Immunol 2008;122:254-60, 260.e1-7.

39. IOC Medical Commission. The International Olympic Committee anti-doping rules applicable to the Games of the XXIX Olympiad, Beijing 2008. Lausanne (Switzerland): IOC; 2008. Available: http://multimedia.olympic.org/pdf/en_report _1316.pdf (accessed 2008 Aug 7)

40. World Anti-Doping Agency. The World Anti-Doping code: the 2008 prohibited list. Montreal (QC): The Agency; 2007. Available: www.wada-ama.org/rtecontent /document/2008_LIST_EN.pdf (accessed 2008 Aug 7).

41. Bonini S, Bonini M, Bousquet J, et al. Rhinitis and asthma in athletes: an ARIA document in collaboration with GA2LEN. Allergy 2006;61:681-92.

42. Parmelee-Peters K, Moeller JL. Gastroesophageal reflux in athletes. Curr Sports Med Rep 2004:3:107-11.

43. Kuehn BM. Education key to treating airway disease: focus on inhaler users, rescue workers, athletes. JAMA 2007;298:2601-8.

44. World Health Organization. Guidelines for safe recreational-water environment: swimming pools, spas and similar recreational-water environments. Geneva: The Organization; 2000. Available: www.who.int/water_sanitation_health/bathing /recrealI-intro.pdf (accessed 2008 Aug 5).

45. Haney S, Hancox RJ. Rapid onset of tolerance to beta-agonist bronchodilation. Respir Med 2005;99:566-71.

46. Subbarao P, Duong M, Adelroth E, et al. Effect of ciclesonide dose and duration of therapy on exercise-induced bronchoconstriction in patients with asthma. J Allergy Clin Immunol 2006;117:1008-13.

47. Fitch KD. $\beta_{2}$-Agonists at the Olympic Games. Clin Rev Allergy Immunol 2006;31: 259-68.

48. McKenzie DC, McLuckie SL, Stirling DR. The protective effect of continuous and interval exercise in athletes with exercise-induced asthma. Med Sci Sports Exerc 1994;26:951-6.

Correspondence to: Dr. Donald. C. McKenzie, Professor and Director, Division of Sports Medicine and School of Human Kinetics, University of British Columbia, 3055 Wesbrook Mall, Vancouver BCV6T 1Z3; don.mckenzie@shaw.ca 